\title{
Influence of oxic/anoxic condition on sorption behavior of PFOS in sediment
}

\author{
Isaac Ayodele Ololade ${ }^{\mathrm{a}, \mathrm{b}, 1}$, Qin Zhou ${ }^{\mathrm{a}, 1}$, Gang Pan ${ }^{\mathrm{a}, *}$ \\ ${ }^{a}$ Research Center for Eco-Environmental Sciences, Chinese Academy of Sciences, Beijing, 100085, China \\ b Chemistry and Industrial Chemistry Department, Adekunle Ajasin University, Akungba-Akoko, Ondo State, Nigeria
}

\section{H I G H L I G H T S}

- The variation of redox potential affects $\mathrm{pH}$ and dissolved organic carbon of sediment.

- The variation of oxic and anoxic environment change the sediment component.

- Whether or not oxic condition promotes PFOS uptake depends on the component amount.

\section{A R T I C L E I N F O}

\section{Article history:}

Received 11 May 2015

Received in revised form

12 August 2015

Accepted 22 August 2015

Available online 5 September 2015

Handling Editor: J. de Boer

\section{Keywords:}

Sediment components

Oxic condition

Anoxic environment

PFOS

Sorption

\begin{abstract}
A B S T R A C T
Sediment components and redox properties change with oxic/anoxic condition, which affect the environmental transport of perfluorooctane sulfonate (PFOS). Herein, the influence of oxic/anoxic condition on the variation of redox and residual components of sediments, where organic matter, iron and manganese oxides are separated from the original sediment collected from Lake Taihu, China, are investigated. Meanwhile, the distinguishing sorption behaviors of PFOS on various residual sediments under oxic and anoxic condition are studied. Sediment after extracting iron and manganese $\left(\mathrm{S}_{\text {-FeMn }}\right)$, which possessed the highest organic carbon $(0.99 \%)$, had the highest affinity for PFOS under oxic condition. However, anoxic environment resulted in an increase of the $\mathrm{pH}$, dissolving of organic carbon and deprotonation of $\mathrm{S}_{\text {-FeMn }}$, which caused the lower sorption capacity of PFOS on S-FeMn. Sediment after extracting manganese $\left(\mathrm{S}_{-\mathrm{Mn}}\right)$ had the higher sorption ability in anoxic environment because the $\mathrm{Fe}^{2+}$ from $\mathrm{S}_{\text {-Mn }}$ provided more effective electrostatic sites for anionic PFOS. When the environment changed to oxic condition, the iron existed as trivalent form in $\mathrm{S}_{-\mathrm{Mn}}$, which resulted in a block of effective sorption site and reduced the sorption amounts of PFOS. The higher percentage of manganese oxides restrained the sorption of PFOS. Hence, whether or not oxic/anoxic condition promoted the PFOS sorption depended on both the percentage and form of various components in the sediment. The study generated further insight into the environmental transport of PFOS in the sediments with different properties and the wetland system, where oxic/anoxic subsurface flow was constructed.
\end{abstract}

() 2015 Elsevier Ltd. All rights reserved.

\section{Introduction}

Perfluorooctane sulfonate (PFOS, $\mathrm{C}_{8} \mathrm{~F}_{17} \mathrm{O}_{3}{ }^{-}$) is an emerging pollutant which has drawn considerable scientific and public concerns and has been detected in water and sediment environment (Ahrens et al., 2010; Beskoski et al., 2013; Pan et al., 2014; Ahrens et al., 2015). In the aquatic environment, PFOS behaves in a

\footnotetext{
* Corresponding author.

E-mail address: gpan@rcees.ac.cn (G. Pan).

1 These authors contributed to the work equally and should be regarded as cofirst authors.
}

hydrophobic fashion and binds with sediment, rather than remaining in the aqueous phase (Higgins and Luthy, 2006). Sorption of PFOS on sediment is a significant process because it affects the fate and environmental transport of PFOS.

Sediment particles consist of organic matter and minerals which include clay minerals, iron oxides and manganese oxides and so on. Each of these components plays different role in the sorption of organic contaminants ( $\mathrm{Li}$ and Werth, 2001), and the scavenging capacities depends on their percentage in the sediment. Higgins and Luthy (2006) indicated that sorption of PFOS on sediments was correlated with the organic carbon content. However, other authors argued that the inorganic materials such as the metal 
oxides affected the fate and transport of PFOS (Johnson et al., 2007; Zhao et al., 2014). The minerals might indirectly reduce the sorption capability of organic pollutants by blocking sorption sites (Bonin and Simpson, 2007). However, these studies were undertaken under oxic condition which were different from the natural environment (anoxic ambient).

The redox potential (Eh) and $\mathrm{pH}$ of the system affect the sorption behavior of PFOS on sediment. Therefore, the sorption of PFOS under anoxic condition is very vital due to dynamic changes of redox conditions during the process of sedimentation. As a result, variations take place in the format of the chemical composition of sediments. Eventually, these variations in local conditions affect the processes of migration and precipitation of chemical substances in water body and sediment. For example, the iron exists in the form of the precipitation of the ferric hydroxide, which blocks the effective sorption sites to reduce the uptake amounts in the oxic environment. However, $\mathrm{Fe}^{2+}$ was an important factor to remove a variety of organic and inorganic pollutants in natural anoxic condition (Rugge et al., 1998; Strathmann and Stone, 2000). The existence of $\mathrm{Fe}^{2+}$ improved the electrostatic interactions between the anions and the free iron oxide (Fink et al., 1970). The two contradictory results derived from the unilateral research which neglected the influence of natural environmental condition (oxic and anoxic) on the composition with different formation, which consequently affected the sorption behavior of PFOS on sediment. To some degree, the resulting distribution parameters and mechanism is unilateral considering the fact that the environmental condition at the sediment-water interface is mostly anoxic. Therefore, a detailed understanding of the transport and fate of PFOS in sediment must include the interaction with iron oxides, manganese oxides and organic matter on actual anoxic condition.

To the best of our knowledge, little is known about the influence of oxic or anoxic condition on the sorption behavior of PFOS on sediments with different components. Therefore, the objectives of this study are (1) to generate further insight into the partitioning and fate of PFOS as it happens in natural ambient condition (oxic and anoxic environment) in the subsurface environment and (2) to understand the relative contributions of the various sediment components to PFOS sorption and the interactions between these components, which influence PFOS fate.

\section{Materials and methods}

\subsection{Standards and reagents}

The potassium salt of perfluorooctane sulfonate (PFOS, 98\%) and ammonium acetate (99\%) were purchased from Fluka (Milwaukee, WI, USA). Sodium perfluoro-[1,2,3,4]- ${ }^{13} \mathrm{C}_{4}$-octanesulfonate (MPFOS, $99 \%, 50 \mu \mathrm{g} / \mathrm{mL}$ solution in methanol) was provided by Wellington Laboratories (Canada). HPLC-grade methanol was obtained from Fisher Scientific Chemical (USA). All the other reagents used in the experiment were of analytical grades.

\subsection{Sediment and water sampling}

Surface sediment (top 1-5 cm) was collected from Lake Taihu, China, with a column sediment sampler (Beeker) and was kept in polypropylene (PP) bags at $4 \pm 2{ }^{\circ} \mathrm{C}$ for the succedent analysis. The sediment was freeze-dried and passed through $0.2 \mathrm{~mm}$ sieves before being used. Water sample was collected using a PP bucket pre-cleaned with methanol and Milli-Q water on the same spot of sediment collection, and stored at $4 \pm 2{ }^{\circ} \mathrm{C}$ after filtration.

\subsection{Sediment sequential extraction}

Residual sediments were obtained by extracting organic matter, iron and manganese oxides, respectively. $\mathrm{NH}_{2} \mathrm{OH} \cdot \mathrm{HCl}(0.1 \mathrm{M})$ and $\mathrm{HNO}_{3}(0.01 \mathrm{M})$ were used to remove manganese oxides, and the product was denoted as $\mathrm{S}_{-\mathrm{Mn}}$ (Li et al., 2006). Both iron and manganese oxides were extracted with $0.2 \mathrm{M}$ of $\left(\mathrm{NH}_{4}\right)_{2} \mathrm{C}_{2} \mathrm{O}_{4}$ buffered with $\mathrm{H}_{2} \mathrm{C}_{2} \mathrm{O}_{4}$ at $\mathrm{pH} 3.0$ and shaken in the dark for $4 \mathrm{~h}$, and the product was marked as $\mathrm{S}_{\text {-FeMn }}$ (Pei et al., 2006). Both $\mathrm{NaOCl}(0.1 \mathrm{M})$ and $\mathrm{H}_{2} \mathrm{O}_{2}$ (30\%) were employed to remove organic matter (OM) based on previous reports (Kaiser and Guggenberger, 2003; Mikutta et al., 2005), and the products were denoted as S-OM1 and $\mathrm{S}_{-\mathrm{OM} 2}$, respectively. The samples were centrifuged at $3800 \mathrm{rpm}$ for $30 \mathrm{~min}$, and supernatant was filtered $(0.45 \mu \mathrm{m})$ into $50 \mathrm{~mL}$ of PP tube for the determination of $\mathrm{Fe}$ and $\mathrm{Mn}$. The residual sediments were washed 4 times with filtered lake water (FLW) and air-dried. The extraction efficiency (EE) was calculated by the following equation. Note that the sediment to reagent ratio is $1: 10$.

$E E=\left(C_{p t}-C_{p}\right) / C_{t} \times 100 \%$

where $C_{p t}$ is pseudo-total content; $C_{p}$ is particle content after extraction; $C_{t}$ is total extractable amount. Pseudo-total amounts $\left(C_{p t}\right)$ of $\mathrm{Fe}$ and $\mathrm{Mn}$ were obtained by a flame atomic absorption spectrometer (AA6300, Shimadzu, Japan). The total extractable amounts $\left(C_{t}\right)$ of Fe and $\mathrm{Mn}$ were determined using the modified sequential extraction procedure (Tessier et al., 1979; Yu et al., 2001). Organic matter was quantified by measuring the total organic carbon (TOC) using a TOC-VCPH instrument (Shimadzu, Japan). The cation exchange capacity (CEC) of sediment samples was determined following the conventional methods (Tao et al., 2006).

Specific surface area (BET) of the sample was determined on a surface area and pore size analyzer (ASAP 2000, Micromeritics, USA). The Fourier transform infrared (FTIR) spectrum of the samples were obtained on a FTIR spectrophotometer (NEXUS 670, Nicolet, USA) by $\mathrm{KBr}$ disk (contained $1 \mathrm{mg}$ of the sample and $300 \mathrm{mg}$ of dried $\mathrm{KBr}$ ) with the $400-4000 \mathrm{~cm}^{-1}$ range. The resolution of FTIR spectroscopy was $2.0 \mathrm{~cm}^{-1}$.

\subsection{Water sample preparation and analysis}

Water sample from Lake Taihu was filtered through $0.22 \mu \mathrm{m}$ fiberglass membranes before extraction to remove suspended particles and biota. All the water samples were extracted by solid phase extraction (SPE) with Oasis WAX cartridges (Waters, $6 \mathrm{cc}, 150 \mathrm{mg}$, $30 \mu \mathrm{m}$ ). The extraction procedure followed those were described in previous publication (Ahrens et al., 2010). The SPE cartridges were first preconditioned by passing through $4 \mathrm{~mL}$ of ammonium hydroxide in methanol, $4 \mathrm{~mL}$ of methanol, and then $4 \mathrm{~mL}$ of Milli-Q water in turn. Before loading to the cartridge, the water samples were spiked with $100 \mu \mathrm{L}$ of $1 \mathrm{ng}$ of MPFOS. The cartridges were rinsed with $4 \mathrm{~mL}$ of $25 \mathrm{mM}$ ammonium acetate buffer ( $\mathrm{pH} 4$ ) in Milli-Q water and dried by centrifugation at $3000 \mathrm{rpm}$ for $20 \mathrm{~min}$. The elution was carried out with $4 \mathrm{~mL}$ of methanol and $4 \mathrm{~mL}$ of $0.1 \%$ ammonium hydroxide, and then reduced to $1 \mathrm{~mL}$ under a nitrogen stream.

An ultra performance liquid chromatography-tandem mass spectrometry (UPLC-MS/MS) was used to determine the concentration of PFOS. UPLC system (Waters Corp., USA) was equipped with a C18 column and MS system is a Quattro Premier XE tandem quadrupole mass spectrometer equipped with an electro-spray ionization source. The analytical procedures were reported previously (Zhou et al., 2010, 2013). Spike and recovery experiments were performed to determine the precision and accuracy of the extraction and the analytical procedure. Method recovery rate ranged from $104.6 \%$ to $110.7 \%$ across all experimental conditions. The instrument 
Table 1

Characterization of sediment pretreated by different procedures.

\begin{tabular}{|c|c|c|c|c|c|c|c|c|}
\hline \multirow[t]{2}{*}{ Pretreatments } & \multirow[t]{2}{*}{ Abbre. } & \multirow[t]{2}{*}{$\mathrm{CEC}(\mathrm{cmol} / \mathrm{kg})$} & \multicolumn{2}{|l|}{ TOC (\%) } & \multicolumn{2}{|l|}{$\mathrm{Fe}$} & \multicolumn{2}{|l|}{$\mathrm{Mn}$} \\
\hline & & & Content & $\mathrm{EE}(\%)$ & Content $(\mu \mathrm{mol} / \mathrm{g})$ & $\mathrm{EE}(\%)$ & Content $(\mu \mathrm{mol} / \mathrm{g})$ & $\mathrm{EE}(\%)$ \\
\hline Original & UNTD & 16.87 & 1.13 & & $367.72 \pm 2.94$ & & $46.74 \pm 1.75$ & \\
\hline $\mathrm{NH}_{2} \mathrm{OH} \cdot \mathrm{HCl}$ & $\mathrm{S}_{-\mathrm{Mn}}$ & 11.23 & 0.92 & 18.58 & $299.58 \pm 0.28$ & 28.35 & $17.11 \pm 0.28$ & 79.48 \\
\hline$\left(\mathrm{NH}_{4}\right)_{2} \mathrm{C}_{2} \mathrm{O}_{4}$ & $\mathrm{~S}_{-\mathrm{FeMn}}$ & 9.01 & 0.99 & 12.39 & $165.64 \pm 0.12$ & 84.08 & $16.24 \pm 0.91$ & 81.81 \\
\hline $\mathrm{NaOCl}$ & $\mathrm{S}_{-\mathrm{OM} 1}$ & 8.48 & 0.18 & 84.07 & $339.98 \pm 2.41$ & 11.54 & $42.79 \pm 0.41$ & 10.59 \\
\hline $\mathrm{H}_{2} \mathrm{O}_{2}$ & S-OM2 & 7.71 & 0.24 & 79.76 & $321.71 \pm 1.22$ & 19.14 & $37.82 \pm 0.05$ & 23.93 \\
\hline $\mathrm{C}_{\mathrm{t}}$ & & & 1.13 & 100 & $240.34 \pm 9.43$ & & $37.28 \pm 4.36$ & \\
\hline
\end{tabular}

limit of determination (LOD, signal-to-noise ratio $3: 1$ ) was $2 \mathrm{ng} / \mathrm{L}$, while the limit of quantification (LOQ 10:1 signal-to-noise ratio) was $7 \mathrm{ng} / \mathrm{L}$. The PFOS concentration in FLW was $2.82 \pm 0.02 \mathrm{ng} / \mathrm{L}$.

\subsection{Sorption experiments}

\subsubsection{Oxic sorption}

In this study, oxic condition was achieved only by the spontaneous oxygen exchange between the overlaying water and the atmosphere at room temperature. Briefly, $0.5 \mathrm{~g}$ of dried sediment was added into each $50 \mathrm{~mL}$ of PP tube and mixed with $20 \mathrm{~mL}$ of $0.5 \mathrm{mM}$ $\mathrm{NaCl}$ solution prepared with FLW. The initial concentrations of PFOS ranged from 400 to $1500 \mathrm{ng} / \mathrm{L}$. A volume of $2 \mathrm{~mL} \mathrm{NaN}_{3}$ solution $(200 \mathrm{mg} / \mathrm{L})$ was added to each tube to inhibit any microbial activity. All tubes were shaken for $48 \mathrm{~h}$ at $25 \pm 0.1^{\circ} \mathrm{C}$ in a 2D-shaker at $250 \mathrm{rpm}$ at $\mathrm{pH} 7.0 \pm 0.1$. The tubes were centrifuged at $9000 \mathrm{rpm}$ for $30 \mathrm{~min}$. Supernatant was filtered through $0.22 \mu \mathrm{m}$ PP membrane and analyzed by UPLC-MS/MS. Blank experiments were set up using the same solid-to-water ratios as the samples but without adding PFOS. One control sample with only the test substance in $0.5 \mathrm{mM} \mathrm{NaCl}$ solution (no sediment sample) was subjected to precisely the same steps as the test systems, in order to check the stability of the substance in $\mathrm{NaCl}$ solution and its possible sorption on the surfaces of the vessels. All the experiments, including controls and blanks, were carried out in duplicate. The amount of PFOS adsorbed on sediment $\left(C_{\mathrm{s}}, \mathrm{ng} / \mathrm{g}\right)$ was calculated as followed.

$C_{s}=\left(C_{0}-C_{e}\right) \times V_{0} / M_{s}$

where $C_{0}(n g / L)$ is the initial PFOS concentration; $C_{\mathrm{e}}(\mathrm{ng} / \mathrm{L})$ is the equilibrium PFOS concentration; $V_{0}$ is the initial volume, and $M_{S}$ is the mass ( $\mathrm{g}$ ) of sediment.

\subsubsection{Anoxic sorption}

Two additional PP tubes containing the samples and $\mathrm{NaCl}$ solution were opened as surrogates for the other tubes to determine $\mathrm{pH}$ and oxidation-reduction potential (ORP) prior to the additions of PFOS. All of the tubes were purged continuously with high-purity $\mathrm{N}_{2}$ gas inside the anoxic box to remove dissolved oxygen and then were capped and allowed to stand in darkness for several days. At different interval, the two surrogate tubes were opened inside the $\mathrm{N}_{2}$ atmosphere to determine their $\mathrm{pH}$ and ORP. When the ORP in the surrogate tubes was negative, the other tubes were then injected with a volume of aqueous PFOS solution to obtain different initial concentrations $(400-1500 \mathrm{ng} / \mathrm{L}$ ). The other conditions were as same as the oxic sorption.

\section{Results and discussion}

\subsection{Characterization of original and residual sediments}

The basic characterizations of original and residual sediments were carried out under oxic condition. The treatment of the sediments exhibited highly variable $\mathrm{CEC}, \mathrm{Fe}, \mathrm{Mn}$ and organic matter amounts (Table 1). The trend in CEC was indicative of the extent to which the organic matter of each sediment had been removed. As expected, the lowest level of CEC was observed in sediment treated with $\mathrm{NaOCl}$ and $\mathrm{H}_{2} \mathrm{O}_{2}$, in which the products were recorded as $\mathrm{S}_{-}$ oM1 and S-OM2.

The TOC fraction and the ratio of Fe/Mn of the original sediment were approximately $1.13 \%$ and 8 , respectively. The total amount of extractable $\mathrm{Fe}$ and $\mathrm{Mn}$ oxides from the original sediment was $240.34 \mu \mathrm{mol} \mathrm{Fe} / \mathrm{g}$ and $37.28 \mu \mathrm{mol} \mathrm{Mn} / \mathrm{g}$, respectively. These extractable fractions corresponded to $65 \%$ and $80 \%$ of the pseudototal $\mathrm{Fe}$ and $\mathrm{Mn}$ oxides, respectively. The sediment treated with $\mathrm{NH}_{2} \mathrm{OH} \cdot \mathrm{HCl}$ reagent was recorded as $\mathrm{S}_{-\mathrm{Mn}}$, in which almost $80 \%$ of Mn but just only $28 \%$ of Fe oxides were effectively removed, respectively. Some authors had related the slight removal of Fe oxides by $\mathrm{NH}_{2} \mathrm{OH} \cdot \mathrm{HCl}$ to be partly due to the binding form of $\mathrm{Fe}$ in the sediments and their existence in amorphous or carbonate form (Turner et al., 2004; Guo et al., 2006). Unlike $\mathrm{NH}_{2} \mathrm{OH} \cdot \mathrm{HCl}$, treatment with $\left(\mathrm{NH}_{4}\right)_{2} \mathrm{C}_{2} \mathrm{O}_{2}$ removed over $80 \%$ each of $\mathrm{Fe}$ and Mn oxides from the original sediment and only about $12 \%$ of organic matter was extracted simultaneously, in which the product was recorded as $\mathrm{S}_{\text {-FeMn }}$.

The two approaches towards extracting the organic matter effectively removed more than $79 \%$ of the organic matter in each case. However, about $19 \% \mathrm{Fe}$ and $24 \%$ Mn were simultaneously removed by $\mathrm{H}_{2} \mathrm{O}_{2}$ compared with about $11 \%$ each of $\mathrm{Fe}$ and $\mathrm{Mn}$ removed by $\mathrm{NaOCl}$ treatment. These treatments showed that it was impossible to completely isolate either of the minerals, Fe or Mn, without interference with each other.

\subsection{Variation in $p H$, redox potential}

The $\mathrm{pH}$ values of all the samples system gradually increased while the oxidation-reduction potential (ORP) decreased after the three months of anoxic incubation (Table 2). Reduction reactions consume protons, which may increase the $\mathrm{pH}$ of the sediment solution (Stumm and Sulzberger, 1992). The Eh values of all the samples under anoxic condition were below the reported critical redox potential for the reduction of $\mathrm{Fe}(\mathrm{Eh}=+300-+100$ at $\mathrm{pH}$ 6-7) (Gotoh and Patrick, 1974), suggesting that reduction of $\mathrm{Fe}^{3+}$ to $\mathrm{Fe}^{2+}$ should have occurred. The extent of reduction varied considerably due to the chemical nature of individual component. Thus, the redox potentials decreased from 271 to $-75 \mathrm{mV}$ in original

Table 2

Experiment condition of sorption under oxic and anoxic environment.

\begin{tabular}{|c|c|c|c|c|c|c|}
\hline \multirow[t]{2}{*}{ Samples } & \multicolumn{2}{|l|}{$\mathrm{pH}$} & \multicolumn{2}{|l|}{ Eh $(\mathrm{mV})$} & \multicolumn{2}{|c|}{ BET $\left(\mathrm{m}^{2} / \mathrm{g}\right)$} \\
\hline & Oxic & Anoxic & Oxic & Anoxic & Oxic & Anoxic \\
\hline UNTD & $6.7 \pm 0.3$ & $7.4 \pm 0.2$ & $271 \pm 30$ & $-75 \pm 22$ & 20.41 & 13.47 \\
\hline $\mathrm{S}_{-\mathrm{Mn}}$ & $4.0 \pm 0.2$ & $5.2 \pm 0.9$ & $306 \pm 49$ & $-17 \pm 15$ & 29.22 & 45.84 \\
\hline $\mathrm{S}_{-\mathrm{FeMn}}$ & $5.4 \pm 0.2$ & $6.8 \pm 0.4$ & $229 \pm 62$ & $-52 \pm 25$ & 34.72 & 10.26 \\
\hline $\mathrm{S}_{-\mathrm{OM} 1}$ & $7.1 \pm 0.3$ & $7.5 \pm 0.3$ & $244 \pm 38$ & $-39 \pm 16$ & 47.29 & 28.97 \\
\hline $\mathrm{S}_{-\mathrm{OM} 2}$ & $6.9 \pm 0.5$ & $7.4 \pm 0.3$ & $311 \pm 56$ & $-12 \pm 23$ & 42.02 & 21.62 \\
\hline
\end{tabular}


sediment (UNTD), from 306 to $-17 \mathrm{mV}$ in $\mathrm{S}_{-\mathrm{Mn}}$, from 229 to $-52 \mathrm{mV}$ in $\mathrm{S}_{-\mathrm{FeMn}}$, from 244 to $-39 \mathrm{mV}$ in $\mathrm{S}_{-\mathrm{OM} 1}$, and from 311 to $-12 \mathrm{mV}$ in S-om2 (Table 2).

Concentrations of $\mathrm{Fe}^{2+}$ and $\mathrm{Mn}^{2+}$ were simultaneously monitored in two replicates containing none of the samples but just the aqueous solution. The drop in redox under anoxic conditions seemed to favor Fe reduction more than Mn reduction at the sediment-water interface as shown by the time-dependent release of iron and manganese to solution (Fig. 1). The increase in dissolved iron as the condition became anoxic represented the reductive dissolution of iron hydroxides that formed during the oxidation experiment. It was noted that the presence of anoxic conditions did not significantly alter the amount of extractable Mn oxides from these sediments.

A general increase in the specific surface area was observed in all the treated samples compared with the original sample, and the higher values being recorded in samples from which the organic matter had been removed significantly ( $\mathrm{S}_{-\mathrm{OM} 1}$ and $\mathrm{S}_{-\mathrm{OM} 2}$ ) under oxic experimental condition (Table 2). This may partly be due to the fact that organic matter destruction uncovered mineral surfaces and rendered them accessible to $\mathrm{N}_{2}$ gas, and also allowed $\mathrm{N}_{2}$ molecules to enter the micropores within the domains. However, $\mathrm{S}_{-\mathrm{Mn}}$ recorded the largest BET area under anoxic condition in contrast to the least value recorded under oxic atmosphere. The least of BET area was found in $\mathrm{S}_{-\mathrm{FeMn}}$ among the treated samples. This was not surprising because as organic matter rich sample, it contained pores of $<0.5 \mathrm{~nm}$ diameter where the diffusion of $\mathrm{N}_{2}$ at $77 \mathrm{~K}$ was kinetically restricted (De Jonge and Mittelmeijer-Hazeleger, 1996). Generally, the decline in specific surface area after reduction was concomitant with the transformation of ferric oxides to soluble $\mathrm{Fe}^{2+}$.

\subsection{Sorption behavior and mechanism}

An interesting finding observed in this study was that oxic/
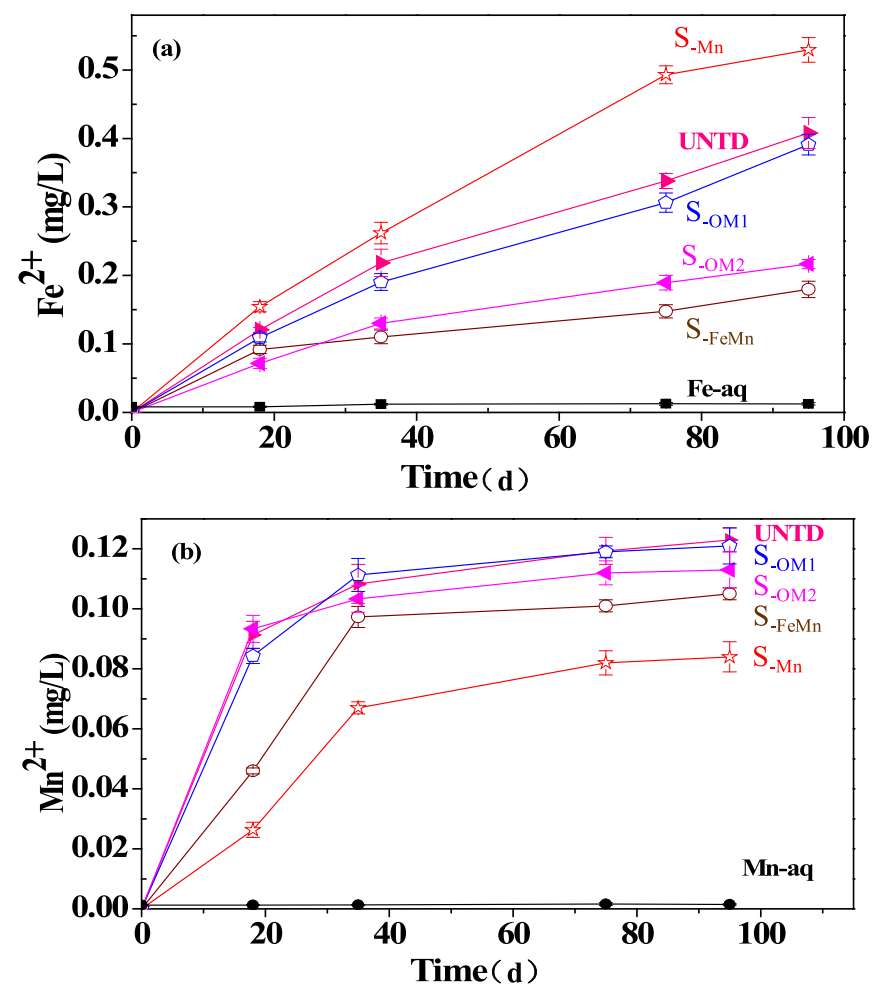

Fig. 1. Aqueous $\mathrm{Fe}^{2+}$ (a) and $\mathrm{Mn}^{2+}$ (b) produced via the reduction of sediment components under $\mathrm{N}_{2}$ atmosphere and $\mathrm{NaN}_{3}$ as microbial inhibitor in anoxic experiment. anoxic conditions had an opposite influence on the sorption of PFOS on the various sediments containing different components. For example, the oxic ambient promoted the sorption of PFOS on S. FeMn. However, the sorption capability of PFOS under anoxic condition was higher than that under oxic condition on $\mathrm{S}_{\text {-Mn }}$ (Fig. 2). The original sorption data of PFOS under oxic and anoxic conditions in different types of sediments were shown in Table S1.

The chemical treatments with ammonium oxalate induced a carboxyl group (COO-) into $\mathrm{S}_{-\mathrm{FeMn}}$, which was obviously observed at $1625 \mathrm{~cm}^{-1}$ in the FTIR (Fig. 3). Thus, apart from removing the mineral component (Fe and $\mathrm{Mn}$ ), the treatment also protonated the carboxylic groups leading to a split of the joint bands of asym with comparatively high intensity (Mikutta et al., 2005). The protonation was contributed to the higher sorption capacity of $S_{\text {-FeMn }}$ in oxic condition. When the environment changed to anoxic condition, the $\mathrm{pH}$ values gradually increased (Fig. 4). The high $\mathrm{pH}$ value had been proved to promote organic matter desorption (Olivie-Lauquet et al., 2001; Gruau et al., 2004). Though S-FeMn had the highest organic carbon (0.99\%) among all the sediments in the oxic environment (Table 1), we found that the organic matter could be mobilized in reductive condition in the $S_{-F e M n}$ (Fig. 4). At the same time, the increase of the $\mathrm{pH}$ values in anoxic condition caused deprotonation of the carboxyl groups at mineral surfaces and thus decreased the positive net surface charge. Consequently, anionic PFOS became more electronegative coupled with repulsion between $\mathrm{S}_{\text {-FeMn }}$ and PFOS. On the whole, the sorption capacity of PFOS on $\mathrm{S}_{\text {-FeMn }}$ decreased with decreasing of the redox potential and increasing of DOC. The result indicated that the samples containing abundant organic matter could effectively scavenge PFOS under oxic condition.

On the contrary, anoxic environment promoted the sorption of PFOS on S-Mn. Though S-Mn had $0.92 \%$ organic carbon, it possessed the higher percentage of residual Mn and Fe (Table 1), respectively. Previous study indicated that high amounts of ferrous and manganous ions were rapidly oxidized in air and tended to precipitate, thereby blocking sorption sites (Toth and Ott, 1970). The decrease of effective sorption sites resulted in a poor sorption capability of PFOS on $\mathrm{S}_{-\mathrm{Mn}}$ in oxic ambient. The aqueous $\mathrm{Fe}^{2+}$ amounts from oxic to anoxic conditions increased from 0 to $0.53 \mathrm{mg} / \mathrm{L}$ after 95 days with nitrogen (Fig. 1). However, the anoxic condition did not significantly alter the amounts of extractable Mn oxides of the sediment components. In anoxic natural habitats, $\mathrm{Mn}^{4+}$ is the only relevant oxidant of $\mathrm{Fe}^{2+}$ (Moraghan and Buresh, 1977; Myers and Nealson, 1988). This residual Mn, in the form of $\mathrm{Mn}^{4+}$ may not be sufficient to significantly oxidize the pre-formed $\mathrm{Fe}^{2+}$ in $\mathrm{S}_{-\mathrm{Mn}}$ under anoxic condition. Thus, the increase of $\mathrm{Fe}^{2+}$ under anoxic conditions was responsible for the significant increase in sorption of PFOS on $\mathrm{S}_{-\mathrm{Mn}}$, which implied the electrostatic attraction between PFOS and $\mathrm{Fe}^{2+}$-species. The study indicated that the sediment containing large number of iron could become important sink for PFOS in anoxic environment.

Another interesting finding was that the isotherm of $\mathrm{S}_{-\mathrm{Mn}}, \mathrm{S}_{-\mathrm{OM} 1}$, $\mathrm{S}_{-\mathrm{OM} 2}$ and UNTD under oxic condition was not from the original point except $\mathrm{S}_{\text {-FeMn }}$ (Fig. 2). This adsorption behavior is due to the native bound adsorbate according a previous study (Pan et al., 2002). The fact that adsorption isotherm could get back to the original point only after the iron composition is removed (Fig. 2) indicated that the native bonded PFOS on iron composition may be responsible for the cross-over type isotherm.

In contrast to the results obtained from $\mathrm{S}_{-F e M n}$ and $\mathrm{S}_{-\mathrm{Mn}}$, the alteration of PFOS concentration seemed to affect the sorption trend on $\mathrm{S}_{-\mathrm{OM} 1}, \mathrm{~S}_{-\mathrm{OM} 2}$ and UNTD (Fig. 2). Anoxic condition was beneficial to sorption of PFOS at the range of low concentration. However, oxic ambient promoted the sorption of PFOS with higher concentration on these three sediments. It was worthwhile to note 

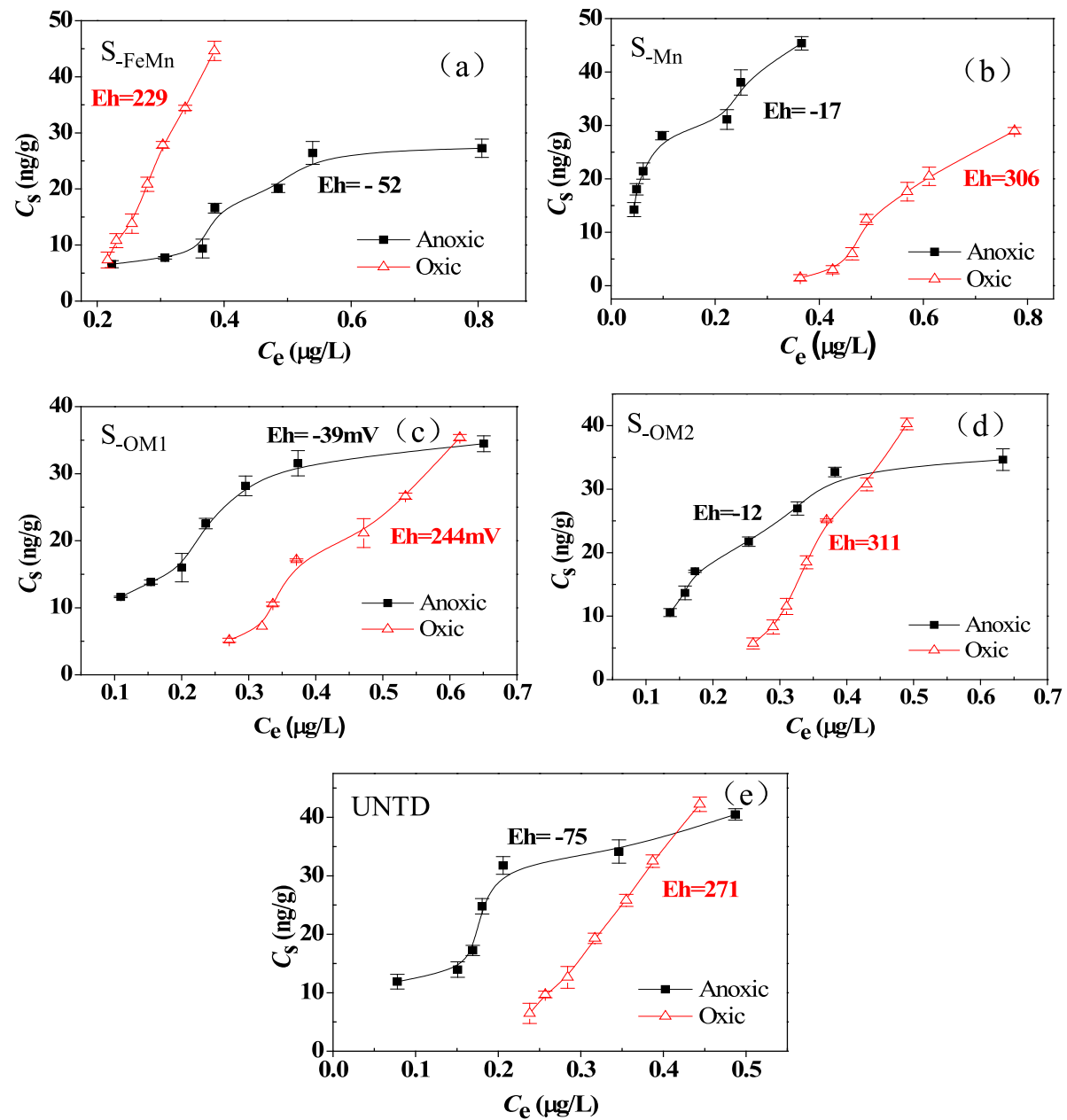

Fig. 2. Comparative sorption of PFOS under oxic and anoxic conditions on different types of sediments (a) $S_{-F e M n}$, (b) $S_{-M n}$, (c) $S_{-O M 1}$, (d) $S_{-O M 2}$, (e) UNTD.

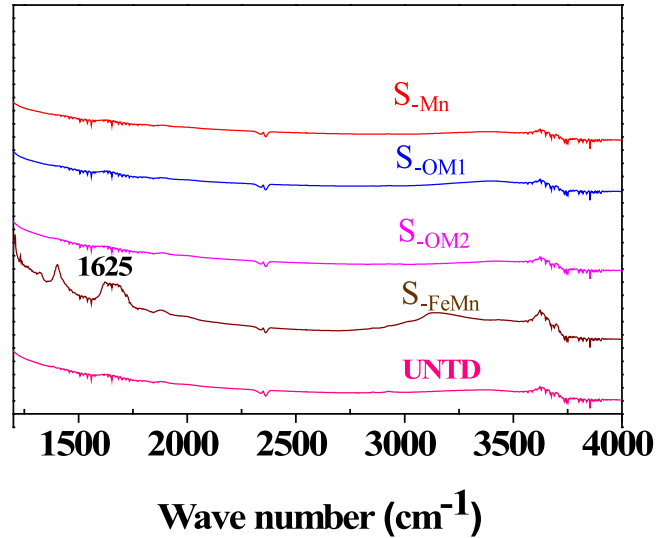

Fig. 3. FTIR spectra of the residual and original samples.

that the PFOS concentration used in the current study was relatively low so that semi-micelle formation was unlikely. Hence, trace level PFOS existed as separate anion. The sorption mechanism discussed above indicated that the hydrophobic partition of PFOS into organic matter on sediments was the primary driving force in oxic ambient. In anoxic environment, the electrostatic attraction between PFOS and $\mathrm{Fe}^{2+}$ was the main driving force during the sorption process. The common feature of these three sediments was that they contained the higher iron and manganese (Table 1).

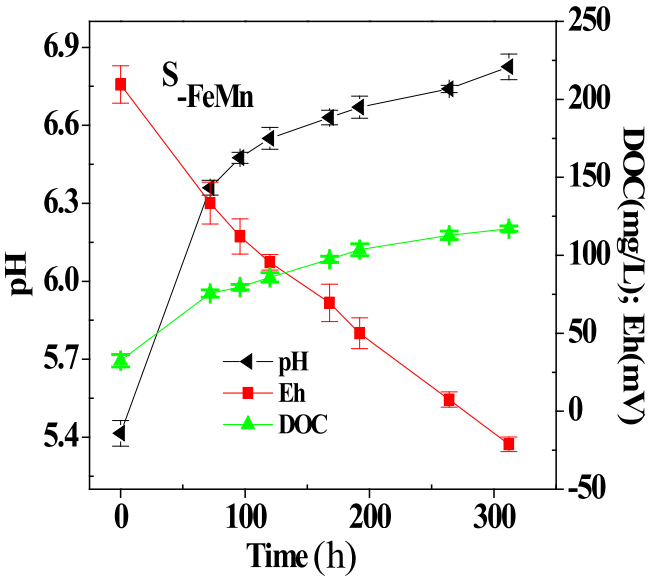

Fig. 4. Nitrogen time-variation of $\mathrm{pH}$, Eh and DOC of $\mathrm{S}_{\text {-FeMn }}$ under anoxic condition.

Hence, it was easy to understand that the sorption capacities of PFOS on S-OM1, S-OM2 and UNTD in anoxic ambient were higher than that in oxic condition because a large amount of $\mathrm{Fe}^{2+}$ in anoxic ambient promoted the sorption of PFOS by electrostatic attraction between $\mathrm{Fe}^{2+}$ and anionic PFOS. When the concentrations of PFOS increased, the sorption on the three types of sediments trended to be saturated. Was it attributed to their lower specific surface areas 
in anoxic ambient? According to the specific BET area of S-OM1 in anoxic condition $\left(28.97 \mathrm{~m}^{2} / \mathrm{g}\right)$ and the lateral area of PFOS molecular $\left(0.25 \mathrm{~nm}^{2} /\right.$ molecular $)$, these sediments supplied enough sorption space for the PFOS within the range of concentration in this experiment. Were the effective sorption sites limited? As mentioned above, the $\mathrm{Fe}^{2+}$ contributed to the high sorption capacity in anoxic condition. A mass of $0.5 \mathrm{~g}$ S-OM1 possessed $169.99 \mu \mathrm{mol}$ of the iron content. Though the effective $\mathrm{Fe}^{2+}$ from $\mathrm{S}$. oM1 in the anoxic environment was only $3.4 \mu \mathrm{mol}$ based on Fig. 1, the effective electrostatic sites supplied by $\mathrm{Fe}^{2+}$ were abundant for PFOS within the range of concentration in this experiment. Hence, what resulted in the gentle sorption of PFOS in the anoxic ambient? As shown in Table 1, the contents of Mn in $\mathrm{S}_{-\mathrm{OM} 1}, \mathrm{~S}_{-\mathrm{OM} 2}$ and UNTD were much higher than that in other sediments. Since the anoxic conditions did not significantly alter the amount of extractable Mn amounts. The manganese oxides, which had more negative surface charge, restrained the interaction of PFOS with sediment particles (Johnson et al., 2007; Becker et al., 2008). In other words, the lower concentration of PFOS was not interfered by manganese oxides, whereas, the manganese oxides to some extent interfered with the PFOS as its concentration increased. Though most organic matter were removed from $\mathrm{S}_{-\mathrm{OM} 1}$ and $\mathrm{S}_{-\mathrm{OM} 2}$, there were still some fractions remained in these residual sediments. Hence, hydrophobic partition of PFOS into organic matter on these sediments happened in oxic environment.

\section{Conclusions}

The sorption system and process were complicated. The variation of oxic and anoxic condition changed the redox properties of system, affected the form of sediment components, and consequently influenced the sorption capacity of PFOS on residual sediment. Whether or not oxic/anoxic condition promoted the sorption of PFOS depended on the percentage of various components of the sediment. Inspecting various factors, the samples containing abundant organic matter but lower amount of Fe and Mn oxides could effectively scavenge PFOS under oxic condition. The sediment containing large number of iron but lower amount of Mn could become important sink for PFOS in anoxic environment. However, anoxic condition promoted the sorption of PFOS at the range of low concentration on the sediment containing large amount of both $\mathrm{Fe}$ and Mn oxides. When the concentration of PFOS increased, negative charges of Mn oxides restrained the interaction of more anionic PFOS and $\mathrm{Fe}^{2+}$-species. In oxic environment, the sorption of PFOS was not interfered by Mn oxides because the hydrophobic partition of PFOS into organic matter was the main driving force.

\section{Acknowledgments}

The study is supported by National Natural Science Foundation of China (Grant No. 41103076, 21277161), TWAS Postdoctoral Fellowship (No: 3240223279), Special Funds of President of the Chinese Academy of Science (No. 312B11YBLWYZJ2011001) and Youth Innovation Promotion Association (29QNCX2012005) of CAS.

\section{Appendix A. Supplementary data}

Supplementary data related to this article can be found at http:// dx.doi.org/10.1016/j.chemosphere.2015.08.068.

\section{References}

Ahrens, L., Norstrom, K., Viktor, T., Palm Cousins, A., Josefsson, S., 2015. Stockholm Arlanda Airport as a source of per- and polyfluoroalkyl substances to water, sediment and fish. Chemosphere 129, 33-38.
Ahrens, L., Taniyasu, S., Yeung, L.W.Y., Yamashita, N., Lam, P.K.S., Ebinghaus, R., 2010. Distribution of polyfluoroalkyl compounds in water, suspended particulate matter and sediment from Tokyo Bay, Japan. Chemosphere 79, 266-272.

Becker, A.M., Gerstmann, S., Frank, H., 2008. Perfluorooctanoic acid and perfluorooctane sulfonate in the sediment of the Roter Main river, Bayreuth, Germany. Environ. Pollut. 156, 818-820.

Beskoski, V.P., Takemine, S., Nakano, T., Beskoski, L.S., Gojgic-Cvijovic, G., Ilic, M., Miletic, S., Vrvic, M.M., 2013. Perfluorinated compounds in sediment samples from the wastewater canal of Pancevo (Serbia) industrial area. Chemosphere 91, 1408-1415.

Bonin, J.L., Simpson, M.J., 2007. Variation in phenanthrene sorption coefficients with soil organic matter fractionation: the result of structure or conformation? Environ. Sci. Technol. 41, 153-159.

De Jonge, H., Mittelmeijer-Hazeleger, M.C., 1996. Adsorption of $\mathrm{CO}_{2}$ and $\mathrm{N}_{2}$ on soil organic matter: nature of porosity, surface area, and diffusion mechanisms. Environ. Sci. Technol. 30, 408-413.

Fink, D.H., Thomas, G.W., Meyer, W.J., 1970. Adsorption of anionic detergents by soils. J. Water Pollut. Control Fed. 42, 265-271.

Gruau, G., Dia, A., Olivie-Lauqueta, G., Davranche, M., Pinay, G., 2004. Controls on the distribution of rare earth elements in shallow groundwaters. Water Res. 38, 3576-3586.

Guo, S.H., Wang, X.L., Li, Y., Chen, J.J., Yang, J.C., 2006. Investigation on Fe, Mn, Zn, Cu, $\mathrm{Pb}$ and $\mathrm{Cd}$ fractions in the natural surface coating samples and surficial sediments in the Songhua River, China. J. Environ. Sci. China 18, 1193-1198.

Gotoh, S., Patrick, W.H., 1974. Transformation of iron in a waterlogged soil as influenced by redox potential and pH. Soil Sci. Soc. Am. J. 38, 66-71.

Higgins, C.P., Luthy, R.G., 2006. Sorption of perfluorinated surfactants on sediments. Environ. Sci. Technol. 40, 7251-7256.

Johnson, R.L., Anschutz, A.J., Smolen, J.M., Simcik, M.F., Penn, R.L., 2007. The adsorption of perfluorooctane sulfonate onto sand, clay, and iron oxide surfaces. J. Chem. Eng. Data 52, 1165-1170.

Kaiser, K., Guggenberger, G., 2003. Mineral surfaces and soil organic matter. Eur. J. Soil Sci. 54, 219-236.

Li, F.M., Wang, X.L., Li, Y., Guo, S.H., Zhong, A.P., 2006. Selective extraction and separation of Fe, Mn oxides and organic materials in river surficial sediments. J. Environ. Sci. China 18, 1233-1240.

Li, J., Werth, C.J., 2001. Evaluating competitive sorption mechanisms of volatile organic compounds in soils and sediments using polymers and zeolites. Environ. Sci. Technol. 35, 568-574.

Mikutta, R., Kleber, M., Kaiser, K., Jahn, R., 2005. Review: organic matter removal from soils using hydrogen peroxide, sodium hypochlorite, and disodium peroxodisulfate. Soil Sci. Soc. Am. J. 69, 120-135.

Moraghan, J.T., Buresh, R.J., 1977. Chemical reduction of nitrite and nitrous-oxide by ferrous iron. Soil Sci. Soc. Am. J. 41, 47-50.

Myers, C.R., Nealson, K.H., 1988. Microbial reduction of manganese oxides - interactions with iron and sulfur. Geochim. Cosmochim. Acta 52, 2727-2732.

Olivie-Lauquet, G., Gruau, G., Dia, A., Riou, C., Jaffrezic, A., Henin, O., 2001. Release of trace elements in wetlands: role of seasonal variability. Water Res. 35, 943-952.

Pan, C.G., Ying, G.G., Liu, Y.S., Zhang, Q.Q., Chen, Z., Peng, F.J., Huang, G.Y., 2014. Contamination profiles of perfluoroalkyl substances in five typical rivers of the Pearl River Delta region, South China. Chemosphere 114, 16-25.

Pan, G., Krom, M.D., Herut, B., 2002. Adsorption-desorption of phosphate on airborne dust and riverborne particulates in east mediterranean seawater. Environ. Sci. Technol. 36, 3519-3524.

Pei, Z.G., Shan, X.Q., Wen, B., Zhang, S.Z., Yan, L.G., Khan, S.U., 2006. Effect of copper on the adsorption of p-nitrophenol onto soils. Environ. Pollut. 139, 541-549.

Rugge, K., Hofstetter, T.B., Haderlein, S.B., Bjerg, P.L., Knudsen, S., Zraunig, C., Mosbaek, H., Christensen, T.H., 1998. Characterization of predominant reductants in an anaerobic leachate-contaminated aquifer by nitroaromatic probe compounds. Environ. Sci. Technol. 32, 23-31.

Strathmann, T.J., Stone, A.T., 2000. Abiotic reduction of oxime carbamate pesticides by Fe(II): catalytic role of mineral surfaces. Abstr. Pap. Am. Chem. Soc. 219, U620.

Stumm, W., Sulzberger, B., 1992. The cycling of iron in natural environments considerations based on laboratory studies of heterogeneous redox processes. Geochim. Cosmochim. Acta 56, 3233-3257.

Tao, Q.H., Wang, D.S., Tang, H.X., 2006. Effect of surfactants at low concentrations on the sorption of atrazine by natural sediment. Water Environ. Res. 78, 653-660.

Tessier, A., Campbell, P.G.C., Bisson, M., 1979. Sequential extraction procedure for the speciation of particulate trace-metals. Anal. Chem. 51, 844-851.

Toth, S.J., Ott, A.N., 1970. Characterization of bottom sediments - cation exchange capacity and exchangeable cation status. Environ. Sci. Technol. 4, 935-939.

Turner, A., Millward, G.E., Le Roux, S.M., 2004. Significance of oxides and particulate organic matter in controlling trace metal partitioning in a contaminated estuary. Mar. Chem. 88, 179-192.

Yu, K.C., Tsai, L.J., Chen, S.H., Ho, S.T., 2001. Chemical binding of heavy metals in anoxic river sediments. Water Res. 35, 4086-4094.

Zhao, L.X., Bian, J.N., Zhang, Y.H., Zhu, L.Y., Liu, Z.T., 2014. Comparison of the sorption behaviors and mechanisms of perfluorosulfonates and, perfluorocarboxylic acids on three kinds of clay minerals. Chemosphere 114, 51-58.

Zhou, Q., Deng, S.B., Fan, Q., Zhang, Q.Y., Yu, G., Huang, J., 2010. Sorption of perfluorooctane sulfonate and perfluorooctanoate on activated sludge. Chemosphere 81, 453-458.

Zhou, Q., Pan, G., Zhang, J., 2013. Effective sorption of perfluorooctane sulfonate (PFOS) on hexadecyltrimethylammonium bromide immobilized mesoporous $\mathrm{SiO}_{2}$ hollow sphere. Chemosphere 90, 2461-2466. 